\title{
Perceiving "ghost" images: a unique case of visual allesthesia with hemianopsia in mitochondrial disease
}

This article was published in the following Dove Press journal:

Neuropsychiatric Disease and Treatment

5 June 2014

Number of times this article has been viewed

\author{
Hidetomo Murakami' \\ Hiroo Ichikawa ${ }^{2}$ \\ Azusa Sugimoto' \\ Akinori Futamura' \\ Yuki Shimizu² \\ Masayuki Sugie ${ }^{2}$ \\ Michael W Miller ${ }^{3}$ \\ Mitsuru Kawamura' \\ 'Department of Neurology, Showa \\ University School of Medicine, Tokyo, \\ Japan; ${ }^{2}$ Department of Neurology, \\ Showa University Fujigaoka Hospital, \\ Yokohama, Japan; ${ }^{3} \mathrm{MD} / \mathrm{PhD}$ Program, \\ University of Tokyo Postgraduate \\ School of Medicine, Tokyo, Japan
}

\begin{abstract}
A 49-year-old man with mitochondrial disease presented with visual allesthesia, a rare and puzzling phenomenon. He was admitted for treatment because of convulsions. After the convulsions ceased, he exhibited left homonymous hemianopsia. Brain diffusion-weighted magnetic resonance imaging (MRI) showed a high-intensity area in the right occipital lobe. Both the hemianopsia and the MRI activation in this area disappeared by day 36 of hospitalization. On the morning of day 57, right homonymous hemianopsia emerged in a singular manner. The patient perceived an illusory object (a bottle placed by the bedside) in his left visual field, while the real object was in his blind right field. This case of visual allesthesia was accompanied by palinopsia, ie, perseveration of the image of the bottle. Diffusion-weighted MRI showed a new, high-intensity area in the left occipital lobe. We believe the visual allesthesia resulted from transfer of cortical information obtained by blindsight between hemispheres as a result of epileptic excitation.
\end{abstract}

Keywords: visual allesthesia, blindsight, palinopsia, mitochondrial disease, epilepsy

\section{Introduction}

Allesthesia is a condition in which a stimulus is perceived at a location remote from its application. It is usually reported in association with somatic stimuli. ${ }^{1}$ There is an early report of visual allesthesia by Beyer in $1895^{2}$ and this case was introduced by Herrmann and Pötzl in $1928 .{ }^{3}$ Following this early observation, we believe there have been at least seven other cases. ${ }^{4-10}$ The etiology is unknown, but possible links have been established with migraine, ${ }^{2}$ arteriovenous malformation, ${ }^{4-6}$ meningioma, ${ }^{7}$ metastatic brain tumor, ${ }^{8}$ gunshot injury, ${ }^{9}$ and neurocysticerosis. ${ }^{10}$ Previously, no patient with both mitochondrial disease and visual allesthesia has been reported. Our patient who had mitochondrial disease, accompanied by hemianopsia, showed episodic visual allesthesia in which objects on his blind side were perceived contralaterally. Furthermore these contralateral, "ghost" perceptions were followed by palinopsia, or visual perseveration. We considered the possible pathophysiology of visual allesthesia in this patient.

\section{Case report}

A 49-year-old man was admitted to our hospital because of convulsions. At age 35, he had been diagnosed with diabetes mellitus and began to take oral anti-diabetic drugs. He also received surgical replacement of the intraocular lenses due to bilateral juvenile cataracts. At age 46, his first generalized convulsion occurred, and he was diagnosed with cerebellar ataxia with arteriovenous malformation in the cerebellar vermis. Following this, he took phenobarbital and zonisamide, but experienced generalized 
convulsions five to ten times a year. The arteriovenous malformation was treated with gamma knife within 6 months of diagnosis, and gradually reduced in size.

Furthermore, on the morning of admission the patient developed general tonic-clonic convulsions. The left homonymous hemianopsia revealed itself about 2 hours after the convulsions stopped. Cerebellar ataxia in limbs and trunk, and ataxic dysarthria were also observed. Other physiological and neurological findings were normal. Brain computed tomography (CT) on admission showed a mild low-density area in the right occipital lobe, and brain magnetic resonance imaging (MRI) (T2-weighted and diffusionweighted images [Figures $1 \mathrm{~A}$ and B]) showed a high-intensity area in the right occipital lobe. Eventually, he was diagnosed with mitochondrial disease with cerebellar ataxia because of repeated convulsions, stroke-like episodes with characteristic radiological findings, and intrathecal high concentrations of lactic acid and pyruvic acid. The patient refused muscle biopsy and the pathological findings are unknown. Genetic analysis revealed no mitochondrial DNA mutation at nucleotide positions 3,243 and 8,344. Thus the type of mitochondrial disease is unknown. With continuing use of phenytoin and zonisamide, the left homonymous hemianopsia gradually resolved itself by hospital day 36 . The high-intensity lesion on diffusion-weighted MRI had extended to the right parietal and temporal lobes by hospital day 22 (Figures $1 \mathrm{C}$ and D), then, in parallel with the clinical symptoms, it disappeared by hospital day 36 (Figures $1 \mathrm{E}$ and F).
However, on the morning of hospital day 57, he suddenly complained that his right visual field was blind. Confrontation visual field examination revealed right homonymous hemianopsia. In the afternoon he suddenly saw a bottle in his left visual field, and tried to grasp it but failed. He then realized it was an illusion produced by a bottle placed on a bedside table in his blind, right visual field. He noticed the illusory image without turning to the right. Thus there is no possibility that he saw the bottle in the intact left visual field. The illusory image had the same shape, size, color, and even letters on the label as the real bottle. He also saw a nurse appear in his left intact visual field, but then noticed she was really on his right. Because the entrance to the room was in his right blind visual field and the wall was in his intact visual field, there was no possibility that the nurse had already been seen on the intact visual side and then reappeared. These illusory images were palinoptic and tended to persist a few minutes after the objects were no longer in view. His visual field was re-examined several times by confrontation perimetry using different observers and we confirmed that the right homonymous visual site was still blind. Our diagnosis was visual allesthesia with palinopsia. Furthermore, the visual allesthesia shifted from the blind homonymous site to the contralateral site and was accompanied by palinopsia. Episodes of this unusual visual phenomenon occurred intermittently for a few weeks, while T2-weighted and diffusion-weighted brain MRI showed a high-intensity area in the left parietooccipital lobes (Figures $1 \mathrm{G}$ and $\mathrm{H}$ ). Electroencephalogram
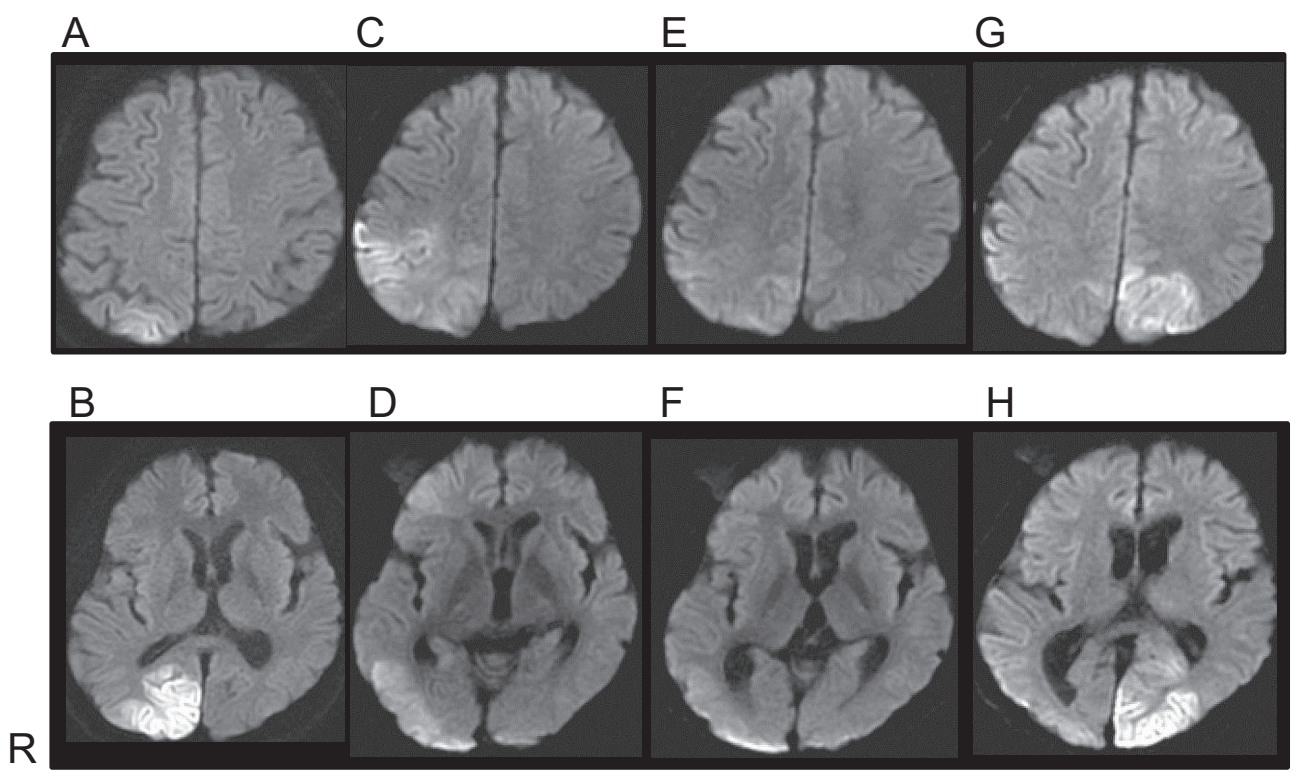

Figure I Brain magnetic resonance imaging (MRI) findings.

Notes: (A and B) MRI (diffusion-weighted image) on admission; (C and D) MRI (diffusion-weighted image) on hospital day 22; (E and F) MRI (diffusion-weighted image) on hospital day 36; and ( $\mathbf{G}$ and $\mathbf{H})$ MRI (diffusion-weighted image) on hospital day 66. Figures in the top set (A, C, E, and $\mathbf{G})$ are images at the cerebral level of corona radiata. Figures in the bottom set (B, D, F, and $\mathbf{H})$ are images at the cerebral level of lenticular nuclei. "R" indicates the right side of the patient's brain. 


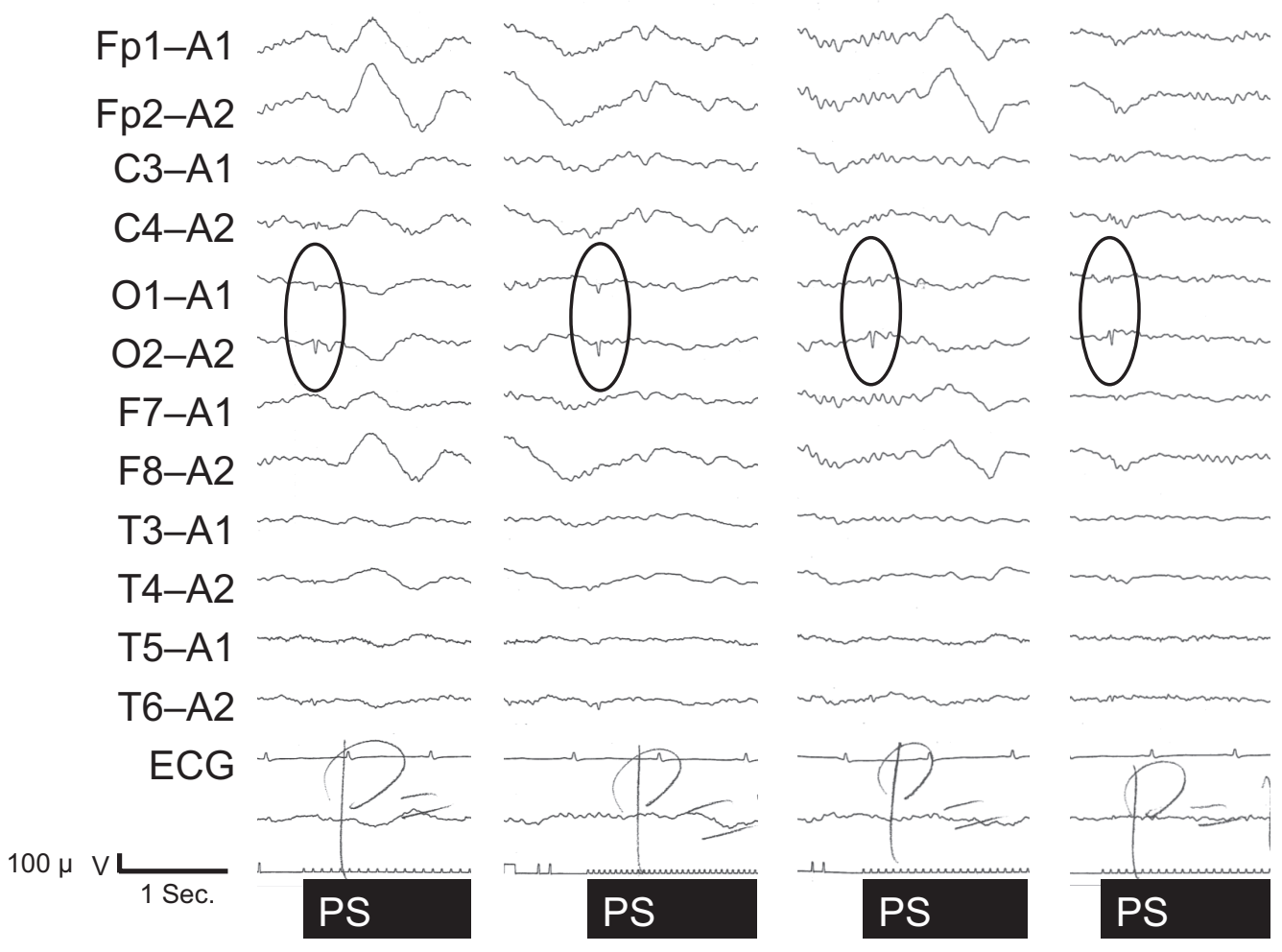

Figure 2 Electroencephalographic findings on hospital day 57.

Note: Positive sharp waves were evoked by photic stimulation in bilateral occipital leads as shown in the ovals.

Abbreviations: ECG, electrocardiogram; PS, photic stimulation; sec, second.

showed positive sharp waves evoked by photic stimulation in bilateral occipital leads (Figure 2).

\section{Discussion}

After the first report in Germany of visual allesthesia in $1895,{ }^{2}$ this interesting phenomenon has rarely been reported. In the later reports, ${ }^{4-10}$ only one case, reported by Ardila et $\mathrm{a}^{10}$ had the direction of shift from blind to the intact visual site. Therefore the shift observed in our case is very rare. A possible explanation, discussed by Ardila et al is that cortical blindness in the hemianopsia field is incomplete. ${ }^{10}$ This was supported by another report ${ }^{11}$ in which a patient with right occipital infarction had an "island" of preserved vision detected only by detailed perimetry, although the patient reported seeing nothing in the area. Thus, partially preserved primary visual cortex may play a role in blindsight. ${ }^{12}$ Since stroke-like lesions in mitochondrial disease are often reversible, incomplete damage of the primary visual cortex may be related to the blindsight of our patient. Meanwhile, alternative mechanisms of blindsight have also been suggested. ${ }^{13}$ The colliculi ${ }^{14}$ and direct projections from the lateral geniculate body to extrastriate visual cortex $^{15}$ are also thought to be involved in blindsight. The involvement of such subcortical structures may be agreeable since the radiologically-proven lesions in our case study were located bilaterally in the occipito-parieto-temporal lobes, but not in the thalamus and brainstem.

The next problem is how vision transferred from the blind to the intact visual field. Ardila et $\mathrm{a}^{10}$ hypothesized that information perceived in the damaged visual cortex (with its island of preserved activity) was transferred to the intact side by epilepsy-linked cortical excitation, and that the "ghost" image was subsequently perceived contralateral to the real image. Furthermore, other case reports of visual allesthesia $^{4-10}$ noted palinopsia, as with our case. In these reports, the pathophysiology of both visual allesthesia and palinopsia is thought to be epileptic in origin. Our patient's condition was also accompanied by seizure and epileptic electroencephalogram findings. We believe epileptic excitation may link the two hemispheres transferring information from the intact island on the blind side to the intact visual area of the contralateral hemisphere.

\section{Conclusion}

This is the first case of mitochondrial disease with visual allesthesia which shifted from blind to intact visual site. Although the etiology of visual allesthesia is unknown, its manifestation in our patient suggests blindsight mediated 
by incomplete cortical impairment and epileptic excitation of cerebral cortex.

\section{Author contributions}

HM, HI, AS, AF, YS, MS and MK clinically assessed the case and performed a literature search. HM, AS, AF, YS and MS drafted the manuscript. HI, MWM and MK revised critically for important intellectual content. All authors agree to the present manuscript. All authors contributed toward data analysis, drafting and revising the paper and agree to be accountable for all aspects of the work.

\section{Acknowledgments}

This study was supported by Grant-in-aids for Scientific Research on Innovative Areas, "Face Perception and Recognition" (MEXT, 23119720) and "The Science of Mental Time" (MEXT, 25119006); and a Grant-in-Aid for Scientific Research (MEXT, 23591283). This study was also supported in part by the Showa University Medical Foundation and the Research Funding for Longevity Sciences (25-13) from the National Centre for Geriatrics and Gerontology (NCGG), Japan.

\section{Disclosure}

The authors report no conflicts of interest in this work.

\section{References}

1. Kawamura M, Hirayama K, Shinohara Y, Watanabe Y, Sugishita M. Allesthesia. Brain. 1987;110(1):225-236.

2. Beyer E. Uber verlagerungen im gesichtsfeld bei flimmerskotom [About displacement in visual field at the time of scintillating scotoma]. Neurol Centralbl. 1895;14:10-15. German.

3. Herrmann G, Pötzl O. Die Optische Allaesthesie: studien zur psychopathologie der raumbildung [The visual allesthesia: studies of pyschopathology of the space forming]. Berlin: Karger; 1928:1-6. German.

4. Jacobs L. Visual allesthesia. Neurology. 1980;30(10):1059-1063.

5. Eretto PA, Schoen FS, Krohel GB, PEchette D. Palinoptic visual allesthesia. Am J Opthalmol. 1982;93(6):801-803.

6. Nakajima M, Yasue M, Kaito N, Kamikubo T, Sakai H. [A case of visual allesthesia]. No To Shinkei. 1991;43(11):1081-1085. Japanese.

7. Arai T, Irie K, Akiyama M, et al. [A case of falcotentorial meningioma with visual allesthesia]. No To Shinkei. 2002;54(3):255-259. Japanese.

8. Critchley M. Types of visual preservation: "Palinopsia" and "Illusory visual spread". Brain. 1951;74(3):267-299.

9. Mendez MF, Chen JW. Epilepsy partialis continua with visual allesthesia. J Neurol. 2009;256(6):1009-1011.

10. Ardila A, Botero M, Gomez J. Palinopsia and visual allesthesia. Intern J Neurosci. 1987;32(3-4):775-782.

11. Fendrich R, Wessinger CM, Gazzaniga MS. Residual vision in a scotoma: Implications for blindsight. Science. 1992;258(5087):1489-1491.

12. Kasten E, Wuest S, Sabel BA. Residual vision in transition zones in patients with cerebral blindness. J Clin Exp Neuropsycho. 1998; 20(5):581-598.

13. Barton JJ. Disorders of higher visual processing. Handb Clin Neurol. 2011;102:223-261.

14. Ptito A, Lepore F, Ptito M, Lassonde M. Target detection and movement discrimination in the blind field of hemispherectomized patients. Brain. 1991;114(1B):497-512.

15. Cowey A, Stoerig P. The neurobiology of blindsight: Trends Neurosci. 1991;14(1B):140-145.
Neuropsychiatric Disease and Treatment

\section{Publish your work in this journal}

Neuropsychiatric Disease and Treatment is an international, peerreviewed journal of clinical therapeutics and pharmacology focusing on concise rapid reporting of clinical or pre-clinical studies on a range of neuropsychiatric and neurological disorders. This journal is indexed on PubMed Central, the 'PsycINFO' database and CAS,

\section{Dovepress}

and is the official journal of The International Neuropsychiatric Association (INA). The manuscript management system is completely online and includes a very quick and fair peer-review system, which is all easy to use. Visit http://www.dovepress.com/testimonials.php to read real quotes from published authors. 